Vol 2, No. 1, 2019

e-ISSN : 2620-9322

\title{
STRATEGI EDU AGROECOPARK TOURISM PADA INDUSTRI RUMAH POTONG HEWAN
}

\author{
Maya Dewi Dyah Maharani \\ Fakultas Ekonomi dan Bisnis, Universitas Sahid \\ Jl. Soepomo No 84, Jakarta Selatan \\ Email Korespondensi: mayasudarsono@gmail.com
}

\begin{abstract}
ABSTRAK
Salah satu manfaat kajian perumusan Strategi Edu Agroecopark Tourism Pada Industri Rumah Potong Hewan Terpadu Kota Bogor sebagai bahan dalam penyusunan inovasi, penelitian dan pengembangan urusan pilihan pertanian (termasuk peternakan dan kesehatan hewan), serta sebagai masukan komponen rencana aksi pada dokumen Rencana Pembangunan Jangka Panjang (RPJP) 2019-2023. Tujuan kajian mendapatkan rumusan dan ukuran keberhasilan Strategi Edu Agroecopark Tourism Pada Industri Rumah Potong Hewan seiring revolusi industri 4.0. Metode kajian menggunakan analisis AWOT yaitu Analytical Hierarchy Process (AHP) dan StrengthWeakness-Oportunity-Threat (SWOT). Hasil analisis AWOT menghasilkan rumusan strategi pelayanan open kitchen Pangan Asal Hewan berbasis budaya higienis dan sanitasi yang terukur dengan score 0,201 untuk menentukan kegiatan-kegiatan wisata, peternakan dan kesehatan hewan yang efektif, dan efisien.
\end{abstract}

Kata kunci: Strategi, RPH, AWOT

\begin{abstract}
One of the benefits of the study of the formulation of the Edu Agroecopark Tourism Strategy in the Animal Slaughterhouse Industry as an ingredient in the preparation of innovations, research and development of agricultural choice affairs (including livestock and animal health), and input of Long Term Development Plan documents (RPJP). The purpose of the study is to get the formulation and measure of success in the Edu Agroecopark Tourism Strategy in the Animal Slaughterhouse Industry along with the industrial revolution 4.0. The study method uses AWOT analysis, namely Analytical Hierarchy Process (AHP) and Strength-Weakness-Oportunity-Threat (SWOT). The results of the AWOT analysis resulted in the formulation of service strategies for open hygienic culture-based Animal Food Kitchen and sanitation with a score of 0.201 to determine effective, efficient and efficient tourism, animal husbandry and animal health activities.
\end{abstract}

Keywords: Strategy, RPH, AWOT 
Vol 2, No. 1, 2019

e-ISSN : 2620-9322

\section{PENDAHULUAN}

Strategi Operasional Edu Agro-Eco-Park Tourism pada industri Rumah Potong Hewan (RPH) merupakan konsep yang relatif baru, karena mengkolaberasikan beberapa harmonisasi dimensi yang meliputi dimensi pendidikan atau $E d u$, pertanian termasuk di dalamnya peternakan dan kesehatan hewan atau Agro, ekologi atau Eco, dalam suatu taman atau Park sebuah lokasi yang sama, serta wisata atau Tourism. Konsep Edu yang dimaksud adalah pendidikan kepada masyarakat agar sensitif memahami bahwa RPH merupakan pintu gerbang industri daging yang memenuhi kriteria Aman-Sehat-UtuhHalal (ASUH), sedangkan bagi pengelola RPH agar memahami kriteria higienitas dan sanitasi dalam proses pemotongan hewan sampai menghasilkan daging. Konsep tourism yang dimaksud meliputi things to see, things to do, things to buy dan things to learn. Di dalam konsep tersebut juga menggambarkan food cycle (dalam hal ini industri daging segar hasil pemotongan hewan di RPH) atau siklus pangan dan industri hijau. Konsep ini merupakan pengembangan dari model Agro-Eco-Industry-Park (AEIP) dari Negara China (Shufang, 2001)

Negara Cina tepatnya di Beijing Xiedao saat ini telah mengembangkan model Agro-Ecology-Industry-Park (AEIP) yang berfokus pada skala usaha industri mikro (termasuk di dalamnya industri daging segar hasil pemotongan dari RPH). Pada tahun 2001, China berada di tahap pertengahan industrialisasi. Oleh sebab itu dalam rangka mewujudkan dimensi ekologi dan pengembangan industri daging segar di lokasi hijau, komponen penggunaan biaya dan sumber daya alam dan lingkungan dikurangi secara bertahap. Berbagai konsep dan implementasi harmonisasi dimensi Agro-Eco-Industry di Indonesia juga sudah dilakukan, diantaranya di Bitung Propinsi Sulawesi Utara, Kota Bogor Propinsi Jawa Barat yang merupakan tantangan industri abad ke-21 menuju industri daging segar dari usaha jasa RPH secara berkelanjutan (Pojoh. et al 2016 dan Maharani et al. 2015)

Seperti kita ketahui bahwa tantangan industri pada abad ke-21 melahirkan konsep industri berkelanjutan, yang pada gilirannya diikuti oleh ekologi industri, sebuah konsep yang mencoba menerapkan sistem ekologi non-limbah untuk produksi industri. Penerapan konsep ekologi industri melahirkan istilah ecoindustrial Park (EIP). Dalam hal produksi dan pengelolaan lingkungan, industri berbasis Agro di kota Bitung dinilai sebagai hal yang baik. Pola hubungan di antara industri adalah masih rendah. Lebih lanjut, model AEIP memprioritaskan alternatif yang mencakup kegiatan industri manufaktur, kerjasama dan pertukaran limbah bahan ternak, unggas, rumah potong hewan, pengomposan, energi terbarukan sebagai sumber pembangkit listrik, dan fasilitas pengolahan air limbah sedangkan desain model dinamis yang menjadi prioritas alternatif 
Vol 2, No. 1, 2019

e-ISSN : 2620-9322

menghasilkan variabel dominan, yaitu: industri fisheriesbased Industry, industri berbasis kelapa, agro-industri, generasi energi terbarukan, dan limbah.

Model AEIP dinamis menunjukkan bahwa pada tahun ke-15, akan mengurangi limbah dan atau meningkatkan penggunaan oleh produk sebagai berikut: (1) mengurangi darah ikan 161.950 liter (24,96\%); (2) mengurangi urin sapi dari 161.950 liter $(6,25 \%)$; (3) kotoran ternak sapi dan ayam sebanyak $2.015 .733 \mathrm{~kg}(94,40 \%)$; (4) meningkatkan penggunaan produk perikanan kelautan sebanyak $24.290 .500 \mathrm{~kg}(93,59 \%)$; (5) produk air kelapa sebanyak 11.803 .600 liter $(93,01 \%)$; (6) tempurung kelapa sebanyak $2.160 .000 \mathrm{~kg}$ (>100\%), dan secara umum (7) menurunkan limbah cair, yaitu santan, darah ikan, dan urin ternak sebanyak 12.127.500 liter (1\% dari limbah cair Total). Adapun langkah yang dapat mempercepat realisasi model pembangunan taman industri di Kelurahan Tanjung merah dan persetujuan Zona ekonomi khusus (KEK) di kota Bitung sedangkan model usaha jasa RPH secara berkelanjutan di Kota Bogor meliputi industri daging segar yang memenuhi higienitas dan sanitasi, pengolahan daging segar menjadi produk olahan, pengomposan, energi baru terbarukan (EBT). Meski konsep AEIP masih belum dijalankan secara utuh di Indonesia, dan memandang bahwa pertumbuhan kegiatan tourism yang saat ini tidak bisa dibendung maka diperlukan perencanaan kolaberasi antara Edu Agro-Eco-Park dengan industri Tourism yang dituangkan dalam Strategi Operasional Edu Agro-Eco-Park Tourism.

Fungsi industri RPH sebagai infrastruktur pintu gerbang pelayanan ketersediaan daging yang berasal dari hewan potong yang sehat dan layak bagi publik, mulai bergeser sebagai salah satu sumber Pendapatan Asli Daerah (PAD). Akibatnya berpeluang besar dan berdampak luas terhadap industri pariwisata. Komponen jumlah dan lama pengunjung menurun karena isu daging yang tidak sesuai dengan kriteria Aman Sehat Utuh Halal (ASUH). Aman mengandung makna bahwa daging yang diproduksi di RPH tidak mengandung bibit penyakit dan bahan kimia ataupun obat-obatan yang dapat menganggu kesehatan. Sehat bermakna daging yang dihasilkan melalui RPH memiliki zat-zat yang bergizidan berguna bagi kesehatan dan pertumbuhan sedangkan Utuh mengandung makna bahwa daging tidak dicampur dengan bagian lain dari hewan lain. Halal berarti daging dijamin dipotong dan ditangani sesuai dengan syariat agama Islam. Dari uraian tersebut di atas, beberapa pertanyaan penelitian adalah sbb:

1) Faktor-faktor apa saja yang berperan penting dan berpengaruh dalam kolaberasi dan harmonisasi Edu Agro-Eco-Park dengan industri pariwisata pada pengelolaan industri usaha jasa RPH?

2) Bagaimana strategi operasional Edu Agro-Eco-Park Tourism yang efektif dalam pengelolaan industri usaha jasa RPH yang perlu dilakukan oleh Pemerintah?

Adapun tujuan penelitian ini adalah untuk merumuskan Startegi Operasional Edu Agro-Eco-Park Tourism pada industri RPH. Pengelolaan keterpaduan antara industri pariwisata dan industri usaha jasa RPH merupakan kolaberasi dan harmonisasi multidimensi yakni dimensi Edu yang menggambarkan things to learn, Agro yang menggambarkan things to buy, Eco yang menggambarkan things to do; dan Park yang menggambarkan things to do. Penerapan Keberlanjutan pada industri RPH atau 
Vol 2, No. 1, 2019

e-ISSN : 2620-9322

Sustainable Operational (SUSOP) yang berkolaberasi dan harmonisasi dengan industri tourism meliputi: (1) pengelolaan risiko terhadap jumlah dan lama kunjungan tourist; (2) mengoptimalkan keuntungan pengelolaan industri usaha jasa RPH melalui kegiatan tourism; (3) meningkatkan pemulihan terhadap sumber daya, utamanya air dan hewan, (4) meningkatkan fungsi-fungsi administrasi pemerintah, (5) mengurangi biaya input operasional, (6) meningkatkan keberlanjutan melalui perumusan dan pelaksanaan SOP, serta (7) memperbaiki keputusan yang mengarah pada perbaikan keberlanjutan pengelolaan industri usaha jasa RPH dan industri pariwisata.

Strategi Operasional Rumah Potong Hewan (RPH) dilaksanakan berdasarkan Standar Nasional Indonesia Nomor 01-6159-1999 dan 01-6160-1999 tentang RPH dan Rumah Potong Unggas (RPU). Strategi tersebut ditindaklanjuti dengan SOP Pemotongan hewan seperti yang tertera pada diagram alir proses pemotongan hewan yang disajikan pada Gambar 1.

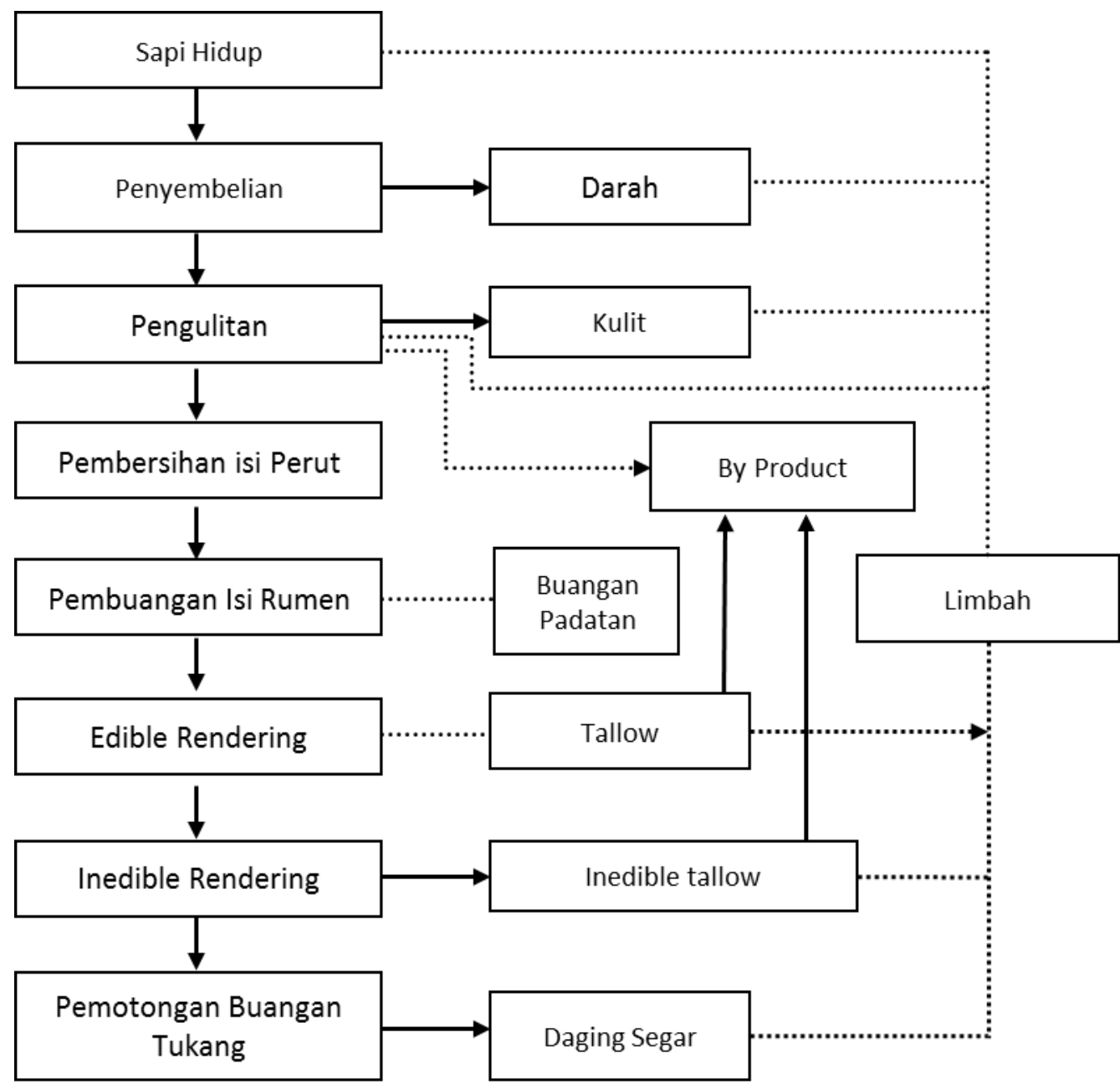

Gambar 1 Diagram Alir Proses Pemotongan Hewan 
Vol 2, No. 1, 2019

e-ISSN : 2620-9322

\section{METODE PENELITIAN}

\section{Rancang Bangun Penelitian}

Rancang bangun penelitian yang digunakan adalah penelitian deskriptif. Rancang bangun ini bertujuan untuk menguraikan karakteristik dan perkembangan industri usaha jasa pemotongan hewan di RPH baik yang dikelola oleh pemerintah maupun swasta, untuk menghasilkan Strategi Operasional Edu Agro-Eco-Park Tourism pada industri RPH. Penelitian ini memerlukan fakta-fakta di lapangan dan data dari pemerintah maupun swasta untuk mendukung analisis strategi operasional yang akurat. Data dan fakta di lapangan dikumpulkan di antaranya dari ASN Pejabat dan Staf RPH, Dinas Pertanian dan pihak pihak yang terkait dalam pengelolaan pemotongan hewan. Desain penelitian deskriptif mampu memberikan informasi terbaru mengenai potensi perubahan perumusan strategi operasional pemotongan hewan, sehingga bermanfaat bagi Pemerintah Daerah dalam rangka meningkatkan PAD yang bersumber dari kegiatan tourism. Selain itu Pemerintah Daerah dapat berupaya menemukan cara baru dalam meningkatkan pemungutan retribusi untuk keperluan pembangunan daerah.

\section{Teknik dan Instrumen Pengumpulan Data.}

Data primer yang dikumpulkan dimaksud untuk mendukung analisis yang dilakukan dengan menggunakan data sekunder. Data primer dikumpulkan melalui FGD, wawancara tidak terstruktur dan kuesioner terhadap pejabat dan pegawai RPH, pegawai dinas, akademisi dan stakeholder. Data primer juga dikumpulkan dari pengamatan di lapangan terhadap proses penyelenggaraan pemotongan hewan.

\section{Metoda Analisis Data}

Metode analisis data yang digunakan adalah metode AHP dan SWOT (AWOT) untuk mendapatkan alternatif strategi operasional Edu Agro-Eco-Park Tourism yang didukung oleh kegiatan-kegiatan yang efektif. Metode SWOT digunakan untuk mengevaluasi faktor-faktor yang menjadi kekuatan (strengths), kelemahan (weaknesses), peluang (opportunities), dan ancaman (threats) yang berpeluang terjadi dan berdampak dalam mencapai suatu tujuan dari program, kegiatan proyek/kegiatan usaha atau institusi/lembaga dalam skala yang lebih luas. Adapun output dari analisis SWOT adalah beberapa rumusan strategi yang dibangun dari kolaberasi faktor-faktor tersebut diatas. Selanjutnya beberapa rumusan strategi operasional tersebut akan disertakan dalam struktur hirarkhi dalam analisis AHP sedangkan metode AHP dilaksanakan dengan prosedur memodelkan problematik menjadi suatu hierarkis yang mengandung tujuan dan sasaran untuk pengambilan alternatif keputusan atau strategi, untuk mencapainya, serta kriteria utama yang dipakai untuk mengevaluasi alternatif-alternatif tersebut. Selanjutnya 
untuk menetapkan prioritas di antara elemen-elemen hierarki dengan jalan membuat serangkaian keputusan berdasarkan pembandingan elemen-elemen tersebut secara berpasangan, mensintesis keputusan-keputusan, untuk menghasilkan seperangkat prioritas dari keseluruhan hierarki, memeriksa konsistensi alternatif keputusan dan mendapatkan keputusan akhir berdasarkan hasil-hasil dari proses di atas.

Perumusan alternatif strategi sebagai proses melibatkan dua bentuk kegiatan, yaitu menetapkan secara umum tentang apa yang akan dilakukan terhadap suatu masalah, dan legal drafting. Beberapa hal yang diperlukan dalam perumusan alternatif strategi adalah: (1) sensitivitas terhadap keadaan dan perubahan lingkungan yang strategis, (2) antisipasi perilaku politik para stakeholders, (3) analisis strategi, dan (4) legal drafting. Adapun yang terlibat dalam perumusan alternatif strategi adalah kelompok kepentingan, peradilan, legislator, komisi dan pemerintah. Selanjutnya analisis strategi mencakup pengkajian persoalan, penentuan tujuan, perumusan alternatif, penyusunan model, penentuan kriteria, penilaian alternatif dan perumusan rekomendasi. Penentuan penilaian alternatif strategi hasil analisis SWOT.

Analytical Hierarchy Process (AHP) adalah salah satu metode analisa data untuk proses memilih alternatif suatu strategi yang dalam hal ini adalah alternatif strategi operasional Edu Agro-Eco-Park Tourism pada pengelolaan industri RPH. AHP dikembangkan oleh Dr. Thomas L. Saaty dari Wharton School of Business pada tahun 1970-an untuk mengorganisisr informasi dan pendapat ahli (judgment) dalam memilih alternatif yang paling disukai (Saaty 1993). Dengan mnggunakan AHP suatu persoalan akan diselesaikan dalam suatu kerangka pemikiran yang terorganisir, sehingga dapat diekspresikan untuk mengambil keputusan yang efektif atas persoalan tersebut. Persoalan yang kompleks dapat disederhanakan dan dipercepat proses pengambilan keputusannya. Prinsip kerja AHP dengan menggunakan program expert choice (Forman EH. 2002) adalah penyederhanaan suatu persoalan kompleks yang tidak terstruktur, strategik, dan dinamik menjadi sebuah bagian-bagian dan tertata dalam suatu hierarki. Tingkat kepentingan setiap variabel diberi nilai numerik, secara subyektif tentang arti penting variabel tersebut dan secara relatif dibandingkan dengan variabel yang lain. Dari berbagai pertimbangan kemudian dilakukan sintesa untuk menetapkan variabel yang memiliki prioritas tertinggi dan berperan untuk mempengaruhi hasil pada sistem tersebut. Untuk menyelesaikan masalah proses memilih alternatif strategi, dilakukan langkah menentukan komponen/elemen/unsur secara hirarki oleh seorang pakar dan FGD.

Selanjutnya berdasarkan penentuan komponen/elemen/unsur yang telah ditentukan oleh pakar, disusunlah hirarki fungsional. Secara grafis persoalan keputusan $A H P$ dapat dikonstruksikan sebagai diagram bertingkat atau hirarki, dimulai dengan membuat goal sasaran pada struktur, dilanjutkan dengan diskusi pakar untuk menentukan dan sekaligus melakukan validasi kriteria utama sebagai level pertama. Kemudian dilanjutkan dengan penentuan sub-kriteria atau aktor pada level kedua, tujuan pada level ketiga, serta alternatif strategis pada level keempat. AHP memungkinkan pengguna untuk memberikan nilai bobot relatif dari suatu kriteria majemuk atau alternatif majemuk terhadap suatu kriteria. Pemberian bobot tersebut secara intuitif, yaitu dengan melakukan 
Vol 2, No. 1, 2019

e-ISSN : 2620-9322

perbandingan berpasangan (pairwise comparison). Dr. Thomas Saaty pembuat AHP kemudian menentukan cara yang konsisten untuk mengubah perbandingan berpasangan menjadi suatu himpunan bilangan yang merepresentasikan prioritas relatif dari setiap kriteria dan alternatif. AHP mempunyai banyak keunggulan dalam menjelaskan proses pengambilan keputusan karena dapat digambarkan secara grafis, sehingga mudah dipahami oleh semua pihak yang terlibat dalam pengambilan keputusan. Dengan $A H P$ proses pengambilan keputusan yang kompleks dapat diuraikan menjadi keputusankeputusan lebih kecil yang dapat ditangani dengan mudah. Selain itu, AHP juga menguji konsistensi penilaian bila terjadi penyimpangan yang terlalu jauh dari nilai konsistensi sempurna, maka hal ini menunjukkan penilaian perlu diperbaiki, atau hirarki harus distruktur ulang.

\section{HASIL DAN PEMBAHASAN}

Hasil analisis AHP pada Tabel 1 memperlihatkan bahwa alternative strategi operasional Edu Agro-Eco-Park Tourism pada pengelolaan industri RPH yang terbesar adalah strategi operasional pelayanan open kitchen Pangan Asal Hewan berbasis budaya higienis dan sanitasi dengan scoring terbesar yakni 0,20.

Tabel 1. Alternatif Strategi Operasional Edu Agro-Eco-Park Tourism pada industri RPH hasil olahan expert choice

\begin{tabular}{|c|c|c|c|}
\hline Kriteria Utama & Nilai & Alternatif Strategi & Nilai \\
\hline $\begin{array}{l}\text { Ketersediaan air dan } \\
\text { hewan potong }\end{array}$ & $\mathbf{0 , 3 1}$ & Pengembangan Kredit Usaha & 0,13 \\
\hline $\begin{array}{l}\text { Jumlah dan lama pengunjung } \\
\text { sebagai tourist }\end{array}$ & 0,20 & $\begin{array}{l}\text { Kemitraan RPH-R dengan } \\
\text { Pelaku Travel Tourism }\end{array}$ & 0,16 \\
\hline Komitmen $H S$ & 0,07 & RPH mobile & 0,16 \\
\hline Pusat pembelajaran $H S$ & 0,12 & $\begin{array}{l}\text { Penataan Taman pada lokasi } \\
\text { RPH }\end{array}$ & 0,19 \\
\hline $\begin{array}{l}\text { Penataan taman pada lokasi } \\
\text { RPH }\end{array}$ & 0,11 & $\begin{array}{l}\text { Pelayanan open kitchen } \\
\text { Pangan Asal Hewan berbasis } \\
\text { budaya higienis dan sanitas }\end{array}$ & $\mathbf{0 , 2 0}$ \\
\hline Penanganan limbah & 0,04 & $\begin{array}{l}\text { Peningkatan diversifikasi Usaha } \\
\text { RPH-R melalui promosi tourism }\end{array}$ & 0,15 \\
\hline Teknologi recycle air & 0,04 & & \\
\hline $\begin{array}{l}\text { Teknologi recycle } \\
\text { spermatozoa epipidemis }\end{array}$ & 0,04 & & \\
\hline Teknologi olahan & 0,05 & & \\
\hline Daya tarik & 0,02 & & \\
\hline
\end{tabular}


Vol 2, No. 1, 2019

e-ISSN : 2620-9322

Selanjutnya prioritas alternatif strategi operasional tersebut layak didukung program prioritas Ketahanan Pangan yang efektif. Prioritas strategi alternatif ke dua adalah penataan taman pada lokasi RPH-R dengan nilai sebesar $(0,19)$. Strategi tersebut dapat direkomendasikan sebagai strategi alternatif pengelolaan industri usaha jasa RPH yang berkolaberasi dan berharmonisasi dengan Edu Agro-Eco-Park Tourism.

\section{KESIMPULAN DAN SARAN}

Strategi Operasional alternatif Edu Agro-Eco-Park Tourism adalah Pelayanan open kitchen Pangan Asal Hewan berbasis budaya higienis dan sanitas layak untuk diwajibkan diterapkan dalam penyelenggaraan keterpaduan antara urusan pilihan pertanian dan urusan wajib pariwisata.

\section{DAFTAR PUSTAKA}

Pojoh, B., Syarief, R., \& Seminar, K. B. (2010). Model Pengembangan Agro-ecoindustrial Park Di Kota Bitung Provinsi Sulawesi Utara. Journal of Industrial Research (Jurnal Riset Industri), 4(1).

Forman, E. H., \& Selly, M. A. (2001). Decision by objectives: how to convince others that you are right. World Scientific.

Maharani, M. D. D. (2018). Model Dinamis Pengelolaan Usaha Rumah Potong Hewan Ruminansia. Jurnal Industri Kreatif dan Kewirausahaan, 1(1).

Saaty, T. L., \& Vargas, L. G. (1994). Decision making in economic, political, social, and technological environments with the analytic hierarchy process (Vol. 7). Rws Pubns.

Wang, S. F., \& Geng, L. P. (2008). Practical model of circular economy-case study from Beijing Xiedao agro-ecological industrial park. Ind. Cluster Meta-Stud, 168172. 